\title{
A Importância da Disciplina de Geografia para a Educação Escolar Indígena
}

The Importance of Geography Discipline for Indigenous School Education

\section{La Importancia de la Disciplina Geográfica para la Educación Escolar Indígena}

Fernanda Cavalcante Gama ${ }^{1}$

Discente: Licenciatura em Pedagogia, Faculdade de Educação da Universidade Federal do Amazonas - UFAM/AM

fernandacgama19@gmail.com http://lattes.cnpq.br/1482079249220712 https://orcid.org/0000-0002-5084-4055

Marilin Pereira de Souza e Souza ${ }^{2}$ Professora: Universidade do Estado do Amazonas - UEA/AM marilinpereira22@gmail.com http://lattes.cnpq.br/9770910899086151 https://orcid.org/0000-0002-0451-889X

Michelle Carneiro Serrão ${ }^{1}$ Professora: Universidade Federal do Amazonas - UFAM/AM michellecserrao@gmail.com http://lattes.cnpq.br/9770910899086151 https://orcid.org/0000-0002-0451-889X

Universidade Federal do Amazonas - UFAM, Brasil ${ }^{1}$

Universidade do Estado do Amazonas - UEA, Brasil ${ }^{2}$ 


\title{
Resumo
}

Este trabalho de estudo tem por finalidade analisar a importância e a contribuição do ensino de Geografia na vida e formação escolar da criança indígena, tendo como objetivo geral: analisar a importância da disciplina de geografia com base no RCNEI Indígena para a educação escolar das crianças indígenas, e específicos: Compreender de que maneira o ensino de geografia atua como propulsor do desenvolvimento escolar indígena; identificar como a geografia na educação escolar indígena atua como instrumento de resistência na luta pela preservação de suas culturas; Discutir a geografia curricular como contribuição para a geografia indígena. O trabalho desenvolvido tem por metodologia a natureza bibliográfica e documental, buscando a compreensão firmada nos documentos que orientam as ações que devem ser vivenciadas no âmbito escolar ao se tratar do ensino de geografia.

Palavras-chave: Geografia. Educação Escolar Indígena. RCNEI

\section{The Importance of Geography Discipline for Indigenous School Education}

\begin{abstract}
The aim of this study is to analyze the importance and the contribution of the teaching of geography in the life and educational formation of the indigenous children, having as general objective: to analyze the importance of the geography discipline based on the Indigenous RCNEI for the education of the indigenous children. and specific: Understand how the teaching of geography acts as a driver of indigenous school development; identify how geography in indigenous school education acts as an instrument of resistance in the struggle for the preservation of their cultures; Discuss curricular geography as a contribution to indigenous geography. The work developed has as methodology the bibliographic and documentary nature, seeking the understanding established in the documents that guide the actions that should be experienced in the school environment when it comes to teaching geography.
\end{abstract}

Keywords: Geography. Indigenous School Education. RCNEI

\section{La Importancia de la Disciplina Geográfica para la Educación Escolar Indígena}

\section{Resumen}

El objetivo de este estudio es analizar la importancia y la contribución de la enseñanza de la geografía en la vida y la formación educativa de los niños indígenas, teniendo como objetivo general: analizar la importancia de la disciplina de la geografía basada en el RCNEI indígena para la educación de los niños indígenas. y específico: Comprender cómo la enseñanza de la geografía actúa como un impulsor del desarrollo escolar indígena; identificar cómo la geografía en la educación escolar indígena actúa como un instrumento de resistencia en la lucha por la preservación de sus culturas; Discuta la geografía curricular como una contribución a la geografía indígena. El trabajo desarrollado tiene como metodología la naturaleza bibliográfica y documental, buscando la comprensión establecida en los documentos que guían las acciones que se deben experimentar en el entorno escolar a la hora de enseñar geografía.

Palabras clave: Geografía. Educación escolar indígena. RCNEI 


\section{INTRODUÇÃO}

O presente trabalho vem evidenciar a importância da disciplina de Geografia para a educação escolar indígena. Sabemos que a educação escolar indígena, assim como a educação não indígena, possui diretrizes.

Hoje temos o Referencial Curricular Nacional para as Escolas Indígenas (RCNEI, 1998). De acordo com o mesmo, ele transpassa todos os eixos e componentes curriculares do ensino escolar e retrata a importância de se trabalhar todos esses eixos de maneira adequada, para potencializar os aprendizados escolares de crianças indígenas.

Dito isto, vamos, no decorrer deste trabalho, entender de que maneira a Geografia como componente curricular auxilia a formação escolar indígena,

Temos como objetivo geral: Analisar a importância da disciplina de Geografia com base no RCNEI para a educação escolar das crianças indígenas. E como objetivos específicos: Compreender de que maneira o ensino de Geografia atua como propulsor do desenvolvimento escolar indígena; identificar como a Geografia na educação escolar indígena atua como instrumento de resistência na luta pela preservação de suas culturas; discutir a Geografia curricular como contribuição para a Geografia indígena.

O estudo da disciplina de Geografia nas escolas deve abordar uma série de questões que envolvam o ser humano, natureza e sociedade. Ensinar Geografia permite com que o educando se reconheça como integrante de um lugar, e dessa forma aprenda a lidar e entender o homem como agente das transformações que ocorrem e que modificam o meio em que vive.

O estudo da Geografia nas escolas indígenas serve para amparar o conhecimento já existente, mas que para os povos indígenas pode ser reconhecido de outra forma. A visão de mundo físico, natural e social está envolvida com a história dos homens, logo, o conhecimento da criança provém dessa relação.

Nesse contexto que a escola, através do professor vai ensinar novas significações e consolidar todos esses conhecimentos. De acordo com o RCNEI de Geografia (1998) "É fundamental que a vivência do aluno seja valorizada e que ele possa perceber que a Geografia faz parte do seu cotidiano, trazendo para o interior da sala de aula, com a ajuda do professor, a sua experiência". (RCNEI, 1998, p.30).

A pesquisa foi qualitativa e teve o caráter bibliográfico, documental. Qualitativa por que trabalha frente a realidades de "um universo de significados, motivos, aspirações, crenças, valores e atitudes, o que corresponde a um espaço mais profundo das relações, dos processos e fenômenos que não podem ser reduzidos a operacionalização de variáveis” Minayo (1994, p. 21 e 22).

A característica da pesquisa documental é que a fonte de coleta de dados está restrita a documentos, escritos ou não, constituindo o que se denomina de fontes primárias (LAKATOS e MARCONI, 2003. p. 174). 
A pesquisa bibliográfica "da mesma forma que as fontes de documentos, as bibliográficas variam, fornecendo ao pesquisador diversos dados e exigindo manipulação e procedimentos diferentes" segundo Lakatos e Marconi (2003. p.183).

Nesse sentido, faremos levantamentos bibliográficos em artigos, e documentos. Assim, nos aportaremos em alguns conteúdos dos gêneros citados acima para fundamentar nossa pesquisa.

\title{
2 A GEOGRAFIA COMO PROPULSORA DO DESENVOLVIMENTO ESCOLAR INDÍGENA
}

De acordo com cada localização, lugar e suas paisagens, as pessoas criam suas maneiras de viver e de usar seus territórios, construindo e moldando seu espaço geográfico. "A Geografia é isso: o povo, os lugares e suas paisagens, e a relação do povo com seu espaço em um determinado tempo histórico" (RCNEI, 1998, p. 225). Dessa forma, percebemos que assim como cada povo se relaciona com o seu espaço, os povos indígenas também fazem esse mesmo processo, utilizando de seu espaço para criar sua própria Geografia, ou seus espaços geográficos.

Sendo assim:

\begin{abstract}
O Brasil é formado por diferentes povos e cada um tem sua forma de viver e ocupar o espaço. Alguns possuem mais tecnologias, outros menos. Uns ocupam grandes áreas, outras áreas pequenas, mas cada um se relaciona com seu espaço e cria a sua Geografia. (RCNEI, 1998, p. 225).
\end{abstract}

Antes de tudo, temos que entender o que é a Geografia. Para melhor compreensão, Geografia para Copatti (2013, p. 19133) é a:

ciência que estuda a superfície terrestre e suas dinâmicas é extremamente importante para que possamos conhecer e compreender o espaço que ocupamos e nossas elações com ele e com os demais seres que o habitam. Contribuiu também na compreensão das relações humanas e destas com o espaço, provocando diferentes olhares sobre o meio e as interações sociais historicamente construídas.

Nesse sentido, buscamos entender que a questão geográfica para os povos originários não é apenas uma questão de ter determinado território denominado seu, mais vai além disso, tudo está interligado e a cultura de cada povo define as características e a forma de apropriação geográfica. De acordo ainda com Copatti (2013, p. 19134), “o ensino da Geografia deve preocupar-se com o espaço nas suas multidimensões, favorecendo a compreensão e a ligação dos fatos conhecidos pelo aluno com os assuntos abordados em sala de aula"

No decorrer das aulas do componente curricular Educação Indígena, no Curso de Pedagogia, da Universidade Federal do Amazonas, que ocorreu no primeiro semestre de 2019, discutiu-se teoricamente sobre educação escolar indígena, interculturalidade, pluralidade cultural, legislação e políticas públicas específicas para esta realidade, assim como diálogo com lideranças indígenas e professores que atuam diretamente com formação de professores indígenas no estado do Amazonas. 
A partir das discussões teóricas, planejou-se uma atividade prática de pesquisa empírica em escolas estaduais ou municipais da cidade de Manaus para verificar se havia crianças indígenas matriculas e caso houvesse, como era desenvolvido o trabalho pedagógico do (a) professor (a). Um dos locais selecionados para pesquisa empírica foi um Centro Indígena localizado na zona urbana de Manaus, em uma área de invasão. Esta área onde se localiza o Centro Indígena é uma invasão, habitada por 14(catorze) etnias, sem demarcação de terra ou qualquer regulamentação por parte do governo.

Houve três momentos de diálogo com professores formadores que aceitaram o convite para dialogar, compartilhar com a turma seus conhecimentos e experiências. Cada professor colaborador participou em dia específico, tendo no seu dia de trabalho, quatro horas para o diálogo, partilha e desenvolvimento de alguma atividade proposta. Compareceram para dialogar com a turma uma liderança indígena Tukano, a Cristina e o Prof. Dr. Gerson Ribeiro Bacury.

Sendo assim, ouvimos atentamente o esforço da professora de utilizar aquele espaço para ensinar os conceitos e noções de Matemática, Ciências, Geografia etc. e notamos o quão é importante o estudo de cada componente curricular e também a relevância da Geografia neste processo de aprendizagem das crianças indígenas.

Neste caso, podemos apontar a compreensão de Pinheiro (2014) que diz,

Trabalhar uma Geografia mais abrangente, onde os povos podem agregar os valores do seu saber, fortalecendo e construindo novas formas de ciência, construído pelos próprios povos indígenas e poder no final ter um produto na língua em que pode ser trabalhado em suas escolas (apud FONTES, 2016, p. 72)

A professora relatou que, aos poucos, as crianças internalizavam procedimentos relevantes da Geografia, que tem um papel fundamental na formação crítica, social e interpessoal das crianças indígenas, pois auxilia no conhecimento de si e do outro, potencializando cada vez mais o desenvolvimento humano em âmbito escolar e social. A Geografia quando trabalhada de maneira adequada, respeitando e considerando a realidade dos alunos, atua como propulsora do desenvolvimento escolar indígena.

\section{DE QUE FORMA A GEOGRAFIA NA EDUCAÇÃO ESCOLAR INDÍGENA ATUA COMO INSTRUMENTO DE RESISTÊNCIA NA LUTA PELA PRESERVAÇÃO DE SUAS CULTURAS}

Primordialmente, necessitamos destacar que a Geografia possui suas particularidades de acordo com o contexto e realidade em que ela está representada. Dependendo da localização, a Geografia se altera. Cada estado, município ou país, possui suas características geográficas e isso implica de maneira direta na vida da população daquele local.

Ou seja, do ponto de vista da Geografia Callai (2005, p. 235) é

a perspectiva para se estudar o espaço: olhando em volta, percebendo o que existe, sabendo analisar as paisagens como o momento instantâneo de uma história que vai acontecendo. Essa é a leitura do mundo da vida, mas que não se esgota metodologicamente nas características de uma Geografia viva e atual, assentada em categorias de análise que supõem a história em si, o movimento dos grupos sociais e a sua interligação por meio da ação ou até de interesses envolvidos.

UFAMBR, Manaus, v. 2, n.1, art. 2, pp. 13-21, janeiro-junho, 2020 http://www.periodicos.ufam.edu.br/ufambr 
Sabemos que o homem é um ser histórico-cultural (LURIA, 1991; MARX, 2001; SAVIANI, 1997), se modifica através do tempo, e assim também modifica o ambiente a sua volta, desta maneira, o indígena transforma o espaço de acordo com suas singularidades.

Algo que devemos levar em consideração, é o fato de como ocorre a educação escolar indígena propriamente dita. Ou seja, o indígena durante séculos permaneceu, guardou e passou seus saberes e conhecimentos, via oral. O indígena possui essa característica marcante em seu âmbito familiar e escolar. Tudo é transmitido através verbalização. Mas não somente. O que garante também a permanência e propagação das línguas maternas e suas culturas.

Sendo assim, percebemos que a Geografia atua sim como um instrumento de resistência importante para manter a valorização da língua materna e suas culturas. É essencial para a resistência dos povos indígenas, afirmando que a sociedade é composta por uma diversidade humana infinita, e que a cultura adquiri formas diversas através do tempo e do espaço Unesco (2002 apud FREITAS, 2010).

O conhecimento geográfico indígena é fundamental pois possibilita decifrar o mundo não indígena. Segundo Bonnin (1999) apud Silva (2011), é “[...] longe de ser uma adesão ao nosso modelo, é neste sentido, uma estratégia de resistência”.

\section{O ENSINO DA GEOGRAFIA COMO CONTRIBUIÇÃO DOS SABERES INDÍGENAS}

Desde os tempos mais remotos, o ser humano teve que se adaptar as transformações que aconteciam na natureza e, com isso, entender como essas transformações também alteravam seus modos de viver. Desta forma, em algum tempo fez se necessário indagar, fazer hipóteses, estudar, para que os estudos desenvolvidos pudessem melhorar sua qualidade de vida (BIESDORF $\mathrm{E}$ WANDSCHEER, 2011).

Sabe-se que o conhecimento na área da Geografia é amplo, e nas escolas indígenas torna-se essencial que haja troca de saberes entre a ciência Geografia e a Geografia indígena, pois

Da vida de cada povo nasce uma Geografia. Os alunos e alunas indígenas, como todos os outros, trazem para a escola seus conhecimentos geográficos. Esse conhecimento deve ser o ponto de partida e de chegada da Geografia na escola. No caminho, há o diálogo entre o conhecimento geográfico do aluno e a Geografia escolar não-indígena. (BRASIL, 1998, p. 216).

A Geografia curricular, ensinada na escola regular, deve ser ensinada de maneira diferenciada na escola indígena, portanto, os conhecimentos sobre a Geografia local são portas para esse diálogo. Dessa forma, cabe analisar situações em que vive cada comunidade, uma vez que cada uma possui formas de se relacionar com o meio, é o que afirma as Diretrizes Pedagógicas da Educação Escolar Indígena do Munícipio de Manaus (2017):

(...) cada povo desenvolve uma estreita relação com a natureza, de forma que a mata, o rio e o igarapé passam a ser extensão de sua casa, pois nesse meio é que são constituídos os saberes tradicionais, que respondem às suas condições de subsistência. (Manaus, 2017, p. 42). 
O RCNEI (1998) explana que trabalhar a Geografia com o público indígena requer esse intercâmbio de saberes, usando a Geografia para explicar o mundo por meio dos estudos no espaço geográfico, pelo que se vê, como as paisagens, os lugares e territórios. Ainda reforça a importância de estudar a Geografia a partir de qualquer ponto significante.

Para tanto, Magalhaes e Neto (2013, p. 13) afirmam que:

O RCNEI procura enfatizar a necessidade de uma elaboração curricular que procura romper com as formalidades rígidas de planos e programas estatísticos, com a formulação de conhecimentos pautados na dinâmica da realidade concreta e na experiência educativa vivida pelos alunos e professores. É necessário considerar o fato de que, mesmo com os fundamentos ora descritos, o RCNEI ainda deve ser "melhorado", com o intuito de fornecer soluções mais seguras para os problemas que envolvem a educação indígena.

Esses estudos contribuem para a formação de um cidadão que conhece os seus direitos e sabe como lutar pela permanência dos mesmos. Importante para conhecer e valorizar o conhecimento tradicional de seu grupo, sobre o seu espaço e sua cultura; para orientação certa no espaço físico e conhecimento de outras formas de orientação; para reflexão sobre a relação de seu povo com os não-índio, conhecimento e dominação da linguagem, a simbologia dos mapas e identificação dos diferentes tipos de mapas, etc. (BRASIL,1998).

\section{CONSIDERAÇÕES FINAIS}

Em nossa pesquisa, buscamos responder aos objetivos propostos de acordo com o apoio bibliográfico de algumas obras. Nesse sentido, fizemos importantes levantamentos em torno de nossa realidade.

Nesse sentido, destacamos o que conseguimos adquirir de resultados até então. Sendo assim, podemos destacar que algo que marcou essa pesquisa foi a importância da Geografia para educação escolar indígena.

Entendemos que a educação e a educação escolar indígena são eixos diferentes, porém ambos são extremamente necessários no desenvolvimento da formação pessoal, social e política dos indivíduos envolvidos nesse contexto.

Segundo Kaercher (1999 apud MAGALHÃES e LANDIM NETO, 2013, p. 84), “a Geografia pode ser um instrumental valioso para elevar a criticidade dos alunos, pois trata de assuntos intrinsecamente polêmicos e políticos, quebrando a tendência secular da escola como algo tedioso e desligado do cotidiano".

Portanto, as discussões em torno da Geografia na educação escolar indígena nos esclareceram que esse eixo da educação é fundamental para a formação integral dos indígenas. Desenvolvida de maneira adequada, tem efeito positivo, esclarecedor e desmistificador, trazendo para as comunidades e povos indígenas a oportunidade de se armarem contra todos e qualquer um que busquem os enganarem de alguma maneira. Lutando pelos seus direitos, pelas suas terras e exercendo seus deveres.

Este trabalho de estudos buscou refletir a importância da disciplina de Geografia como contribuição para a vida e formação escolar da criança indígena. Sabemos que a educação é um direito de todos, 
e com base nisso reafirmamos a educação diferenciada e de qualidade para os povos indígenas. Para que eles sejam capazes de interagir e se integrar ao conhecimento comum, em prol a conquista de seus direitos e sua valorização.

Ao realizarmos esse estudo, nós como acadêmicos e futuros professores também nos apropriarmos destes conhecimentos, não somente da importância da Geografia, mas como todas as outras áreas de ensino, como as disciplinas de língua portuguesa, matemática, história, arte, enfim. No qual cada área tem sua especificidade e valor. Nosso papel é compreender ainda mais os diferentes modos de ensinar, de educar e de se colocar na situação de aprendizagem, enxergando o que está intrínseco na nossa identidade, pregando o valor, o respeito e a autonomia para nossos futuros alunos. Portanto finalizamos dizendo que a Geografia é a visão do homem sobre o meio, suas interações e correlações com o espaço e com a sua própria espécie.

\section{REFERÊNCIAS}

Biesdorf, R. K. \& Wandscheer M. F. (2011). Arte, uma necessidade humana: função social e educativa. Revista eletrônica do curso de pedagogia do Campus Javaí - UFG, v. 2, n. 11.

República Federativa do Brasil. (1998). Base Nacional Comum Curricular para a Educação Indígena. Versão Preliminar. Brasília: MEC, $2017 \_$_ Referencial curricular nacional para as escolas indígenas/ Ministério da Educação e do Desporto. Secretaria de Educação Fundamental. - Brasília: MEC/SEF.

República Federativa do Brasil. (1997). Parâmetros curriculares nacionais: história, geografia / Secretaria de Educação Fundamental. - Brasília: MEC/SEF.

Copatti, C. (2013). Avanços na educação escolar indígena e a contribuição da geografia na construção de uma educação diferenciada. XI Congresso Nacional de Educação, Pontifícia Universidade Católica do Paraná - Curitiba. Recuperado em 24 de jul. de 2019, de https://educere.bruc.com.br/CD2013/pdf/8557_4485.pdf.

Fontes, T. F. (2016). Por uma Geografia Indígena: uma análise do Ensino de Geografianas Licenciaturas Indígenas Interculturais da Universidade Federal do Amazonas. Dissertação de Mestrado, Universidade Federal do Amazonas, Manaus, AM, Brasil. Recuperado em 09 de dez. 2019 de https://tede.ufam.edu.br/handle/tede/5244.

Freitas. I. (2010). A experiência indígena no ensino de história. (org): Oliveira. M.M.D. História: ensino fundamental. Brasília: Ministério da Educação, Secretaria de Educação Básica, 2010 .

Lakatos. E. M \& Marconi. M. A. (2003). Fundamentos da metodologia científica (5a ed) São Paulo: Atlas.

Luria, A. R. (1991). Curso de psicologia geral. Rio de Janeiro: Civilização Brasileira.

Magalhães, G. B. \& Neto, F. O. L. (2013). A geografia e a educação indígena: uma análise dos documentos normativos. Revista Brasileira de Educação Geográfica, 5 (3), 82-97. $\begin{array}{llllll}\text { Recuperado em } & 09 & \text { de } & \text { de } & \text { de }\end{array}$ http://www.revistaedugeo.com.br/ojs/index.php/revistaedugeo/article/view/73.

Prefeitura Municipal de Manaus. (2017). Diretrizes Pedagógicas da Educação Escolar Indígena do Munícipio de Manaus: SEMED. Recuperado em 06 de dez. de 2019, de http://semed.manaus.am.gov.br/wp-content/uploads/2019/07/Diretrizes-da-E-EInd $\%$ C3\%ADgena-do-Munc\%C3\%ADpio-de-Manaus-aprovada-pelo-conselho.pdf

Marx, K. (2001). O Capital: Crítica da Economia Política. (8a ed). Rio de Janeiro: Civilização Brasileira.

UFAMBR, Manaus, v. 2, n.1, art. 2, pp. 13-21, janeiro-junho, 2020 http://www.periodicos.ufam.edu.br/ufambr 
Minayo, M.C.S. (1994). Pesquisa social: teoria, método e criatividade (21a ed). Petrópolis, RJ: Vozes.

Saviani, D. (1997). Pedagogia Histórico-Crítica: primeiras aproximações (6a Ed). Coleção Polemicas do Nosso Tempo. Campinas: Editora Autores Associados.

Silva. R.H.D. (2011). Afinal, quem educa os educadores indígenas?. (Org) Gomes. N. \& Silva. P. B. G. Experiências étnico-culturais para a formação de professores (3a Ed). Belo Horizonte: Autêntica. 